\title{
VIO. STUDY OF THE IMMUNE RESPONSE INDUCED BY DIFFERENT ADJUVANTS.
}

Patrícia Conceição Gonzalez Dias ${ }^{1}$; Tamiris Azamor da Costa Barros ${ }^{1}$; Patrícia Cristina da Costa Neves²; Gabriela Santos Esteves²; Marco Alberto Medeiros².

${ }^{1}$ Instituto Oswaldo Cruz e Bio-Manguinhos - Fiocruz;

${ }^{2}$ Bio-Manguinhos - Fiocruz.

INTRODUCTION The biggest challenge for the development of subunit vaccines based on recombinant or purified proteins is that they have low immunogenicity and mobilize an insufficient immunoprotective response. Adjuvants are used to amplify and direct the immune response. In this study, the protein Lig (Leptospira $s p p$. immunoglobulin-like protein) was used as a model. Studies demonstrate that this antigen corresponds to an OMP that works as a mediator in pathogenic mechanisms, allowing its use in experimental vaccines with success. To optimize immunogenicity of the vaccine based on Lig proteins, a comparative study was conducted between $\mathrm{Al}(\mathrm{OH}) 3$, Nanoparticles (Ca3(PO4)2), Flagellin (flagellar protein) and ISCOM (saponin based) adjuvants.

OBJECTIVE Evaluation and characterization of the immune response induced in mice by different adjuvants in association with rLig protein.

METHODOLOGY The recombinant protein Lig was expressed in E. coli. Purification was performed through IMAC. Mice immunizations with rLig (3 and $30 \mu \mathrm{g} /$ dose) and adjuvants were performed in a two doses regime with a 15-day interval between each dose. Serum were obtained on days 0,14, 29, 59, 89 and on day 119 followed by euthanasia and splenectomy. The kinetic and profile of the humoral immune response was evaluated by ELISA. The avidity of the antibodies was evaluated by ELISA, adding urea. The cellular immune response was evaluated by ELISpot for the detection of IFN- $\gamma$, IL-4, IL-2 and IL-17. Mice splenocytes were harvested in plates in the presence of: (1) $\mathrm{rLig}$, (2) Concanavalin A and (3) in the absence of stimulation. Statistical analysis was performed using GraphPad Prism ${ }^{\circledR} 3.5$ ( $\mathrm{p}$ value $<0.05$ ).

RESULTS Recombinant Lig used in vaccine formulations was obtained with homogeneity above $90 \%$. ELISA assays demonstrated that all adjuvants were able to induce humoral response when compared to negative controls. The immune response 
profile was similar between adjuvants with higher titers after the second immunization, followed by a decline in the titers of circulating antibodies over time, except for the adjuvant $\mathrm{Al}(\mathrm{OH}) 3$ which kept increasing titers throughout the trial period. The biggest titers in ELISA Units per milliliter and avidity index obtained for each adjuvant were: ISCOM (37,036; 83.84), Flagellin with $\mathrm{Al}(\mathrm{OH}) 3$ (14,782; 91.92), Flagellin (13,933; 86.08), $\mathrm{Al}(\mathrm{OH}) 3$ (6287; 89.68) and Nanoparticles Adjuvant (3328; 87.11). The IgG1 isotype was the predominant in all the formulations. However, the formulations with ISCOM and Flagellin in association with $\mathrm{Al}(\mathrm{OH}) 3$ revealed a larger equilibrium between the isotypes. ISCOM was the only adjuvant capable of stimulating a significant cellular immune response compared to the control, stimulating IFN- $\gamma$ and IL-2.

CONCLUSION Overall, this study provided important information to understand the immune response triggered by each adjuvant when associated with recombinant protein Lig, helping in the development of novel vaccines. Furthermore, the obtained data can be used in other immunization models with bacterial antigens.

KEYWORDS adjuvants, subunit vaccines. 